\title{
Qualidade da água no perímetro urbano do córrego das Pitas em Araputanga, MT
}

Estudos sobre a hidrodinâmica e o transporte de sedimentos possibilitam compreender como ocorrem as pressões no meio e a relação entre os elementos ambientais. O objetivo da pesquisa foi analisar as variáveis hidrodinâmicas e transporte de sedimentos na bacia hidrográfica do Rio Branco, afluente do Pantanal mato-grossense. Foram selecionadas dezesseis seções para obtenção de informações da hidrodinâmica e do transporte de sedimentos. Com o intuito de obter a batimetria, utilizou-se o ecobatímetro. A verificação da velocidade do fluxo foi realizada com o uso do molinete fluviométrico. A fim de coletar os sedimentos suspensos, usou-se a garrafa de Van Dorn; para os sedimentos de fundo, utilizou-se a draga Van Veen. O fracionamento das amostras de sedimentos de fundo fo realizado através do método da pipeta, com dispersão total e peneiramento. A vazão dos canais variou entre 0,005 e $4,861 \mathrm{~m}^{3} / \mathrm{s}$ no período de estiagem e de 0,11 a $126,42 \mathrm{~m}^{3} / \mathrm{s}$ no período chuvoso. Os sedimentos transportados em suspensão mantiveram-se entre 12 e $288 \mathrm{mg} / \mathrm{L}-1$. A carga sólida em suspensão ficou entre 0,02 e 3.146 t/dia-1. Na composição granulométrica de sedimentos de fundo, predominaram as frações de areia fina. Através desse estudo foi possível observar o comportamento hídrico e a disposição de sedimentos entre os períodos de cheia e estiagem.

\section{Hydrodynamics and sediment transportation in the Branco river basin, afluente do rio Paraguai, Pantanal Mato-grossensse}

\begin{abstract}
Studies on hydrodynamics and sediment transport make it possible to understand how pressures occur in the environment and the relationship between the environmental elements. The objective of this research was to analyze the hydrodynamic variables and sediment transport in the watershed of Rio Branco, a tributary of the mato-grossense Pantanal. Sixteen sections were selected to obtain information on hydrodynamics and sediment transport. In order to obtain the bathymetry, the echo sounder was used. Flow velocity verification was performed using the fluviometric windlass. In order to collect the suspended sediments, Van Dorn bottle was used; for bottom sediments, we used Van Veen dredger. The fractionation of the bottom sediment samples was performed by the pipette method, with total dispersion and sieving. Channel flow ranged from 0.005 to $4,861 \mathrm{~m}^{3} / \mathrm{s}$ in the dry season and from 0.11 to $126.42 \mathrm{~m}^{3} / \mathrm{s}$ in the rainy season. The suspended sediment remained between 12 and $288 \mathrm{mg} / \mathrm{L}-1$. The solid suspended load was between 0.02 and $3146 \mathrm{t} /$ day- 1 . In the granulometric composition of bottom sediments, the fine sand fractions predominated. Through this study, it was possible to observe the water behavior and the sediment disposition between the periods of flood and drought.
\end{abstract}

Keywords: Granulometry; Tributaries; Solid Suspended Load.

Topic: Hidrogeografia

Reviewed anonymously in the process of blind peer.
Received: 02/02/2018

Approved: 20/05/2018
Josiel Dorriguette de Oliveira

Universidade do Estado do Mato Grosso, Brasil

http://lattes.cnpq.br/6621469465419502

http://orcid.org/0000-0002-5109-6044

josieldorriguette@hotmail.com

\section{Celia Alves de Souza (iD}

Universidade do Estado do Mato Grosso, Brasil

http://lattes.cnpq.br/4260661798494235

http://orcid.org/0000-0002-9068-9328

celiaalvesgeo@globo.com

Juberto Babilônia de Sousa (iD

Instituto Federal de Mato Grosso, Brasil

http://lattes.cnpq.br/0985085839069147

http://orcid.org/0000-0002-2574-1572

jubertobabilonia@yahoo.com.br

\section{Referencing this:}

OLIVEIRA, J. D.; SOUZA, C. A.; SOUSA, J. B.. Hidrodinâmica e transporte de sedimentos na bacia do rio Branco, afluente do rio Paraguai, Pantanal Mato-grossensse. Revista Ibero-Americana de Ciências Ambientais, v.9, n.1, p.223-238, 2018. DOI: http://doi.org/10.6008/CBPC2179-6858.2018.001.0016 


\section{INTRODUÇÃO}

Uma bacia hidrográfica pode ser definida como a área de captação natural da precipitação onde se encontra um conjunto de canais de escoamento, composto pelo rio principal e por seus afluentes que convergem para um único ponto de saída. A área de abrangência de uma bacia é definida pelos pontos mais altos do relevo, onde se formam os divisores de água; assim, as águas da chuva escoam superficialmente, nessa área delimitada pelo relevo, formando e encorpando rios e riachos, ou infiltrando-se no solo para alimentar o lençol freático, que aflora, formando as nascentes (CHRISTOFOLLETI, 1980; BARRELLA et al., 2000; TUCCI, 1997).

Segundo Christofoletti (1980), os rios apresentam-se como canais de escoamento fluvial da água que alcança os cursos d'água, inclusive a que se infiltra no solo, alimentando o lençol subsuperficial posteriormente.

Ainda conforme esse autor a dinâmica fluvial compreende a remoção, o transporte e a deposição das partículas envolvidas em toda a rede de drenagem e incide diretamente sobre o equilíbrio do sistema fluvial. Sua capacidade depende, especialmente, da velocidade e turbulência do fluxo dentro do canal. Os rios podem transportar sedimentos de diferentes maneiras (solução, suspensão e saltação), de acordo com a sua granulometria (tamanho e forma) e com as características do fluxo (turbulência e forças hidrodinâmicas) (CUNHA, 2009). Heitmuller \& Raphelt (2012) reiteram a importância do sedimento na dinâmica fluvial, destacando que é necessária a recuperação de um rio. Em contrapartida, caso haja um desequilíbrio, essa capacidade pode também causar sérios danos.

Négrel et al. (2014), ao fazerem a conexão solo - sedimento - rio definem as principais preocupações para a gestão das bacias hidrográficas, sendo: a erosão, impermeabilização, compactação, salinização, alterações hidromorfológicas, contaminação, alterações na quantidade de água, acidificação e redução da matéria orgânica do solo. Apontam também oito indicadores que podem ser utilizados para a caracterização do estado biofísico da bacia, são eles: a composição química, o estado trófico, o estado da biota, a capacidade da cobertura, a salinidade, o material particulado, o nível da água e a morfologia e pedologia.

Pesquisando sobre a influência da exploração de madeira na mata ciliar de oito córregos afluentes do Rio Middle Fork, em Randolph County, West Virginia, Estados Unidos, Studinskiet al. (2012) não conseguiram observar grandes interferências na sedimentação no período de corte das árvores. Apesar disso, ressalvam cautela pelo curto período de avaliação. O maior impacto observado foi o aumento da temperatura que traz impacto direto a algumas espécies que são sensíveis à mudança de temperatura mesmo que em pequenos perímetros.

Blanton e Marcus (2013), partindo de cinco modelos hipotéticos, bem como da análise histórica da hidrologia e da geomorfologia para não se prender a uma causa única do evento, verificaram que a construção de estradas e ferrovias perpendicular aos rios Chehalise Yakima, em Washington, USA, trouxe o isolamento em alguns trechos das várzeas. Esse fato causou impactos na vegetação ciliar, a qual, em muitos casos, não se restabeleceu, ocasionando relevantes problemas ambientais. 
O estudo realizado por Souza \& Cunha (2012), no Rio Paraguai, mostra que as águas correntes provocam erosão no leito dos rios, por intermédio dos mecanismos de corrosão (química) e corrasão (desgaste abrasivo). Pontuam ainda que a erosão dependa de fatores como velocidade e turbulência do fluxo, do volume e das partículas transportadas nas águas dos rios. Segundo Lima (2010), em rios de leitos rochosos, as duas principais categorias de processos erosivos são a abrasão e o arranque. $\mathrm{O}$ autor afirma que o fluxo de sedimento, além de influenciar o processo erosivo por abrasão, causa a predisposição do leito ao arranque e produz micro fissuras pelo impacto.

Diante da importância dos estudos sobre a dinâmica fluvial e o uso e ocupação da terra nas bacias hidrográficas, alguns trabalhos podem ser destacados, tais como os de: Santos (2014), na bacia hidrográfica do Córrego Cachoeirinha; Andrade \& Souza (2009), analisando a dinâmica fluvial e o processo de ocupação como proposta de gestão dos recursos hídricos na bacia hidrográfica do Córrego das Pitas - MT; Souza \& Cunha (2012), sobre a evolução das margens do rio Paraguai entre a cidade de Cáceres e a estação ecológica da Ilha de Taiamã - MT, Trimble (2009) sobre processos fluviais em contribuinte do Mississipi e Silva (2010) em seus estudos sobre transporte de sedimentos na bacia hidrográfica do rio Ipojuca em Porto de Suape. Dessa maneira este estudo teve como objetivo analisar as variáveis hidrodinâmicas e o transporte de sedimentos na bacia hidrográfica do rio Branco, localizada no estado de Mato Grosso, Brasil.

\section{METODOLOGIA}

\section{Área de Estudo}

A bacia hidrográfica do Rio Branco, está localizada entre as coordenadas geográficas de 14 59'00"

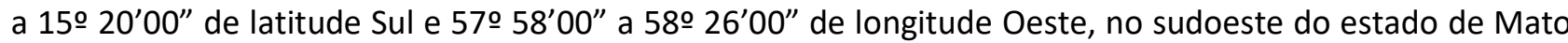
Grosso, Brasil. Com área de aproximadamente $1.027,80 \mathrm{~km}^{2}$, sua nascente principal encontra-se no Planalto dos Parecis. O Rio Branco deságua na margem esquerda do Rio Cabaçal, no município de Lambari D’Oeste (figura 1).

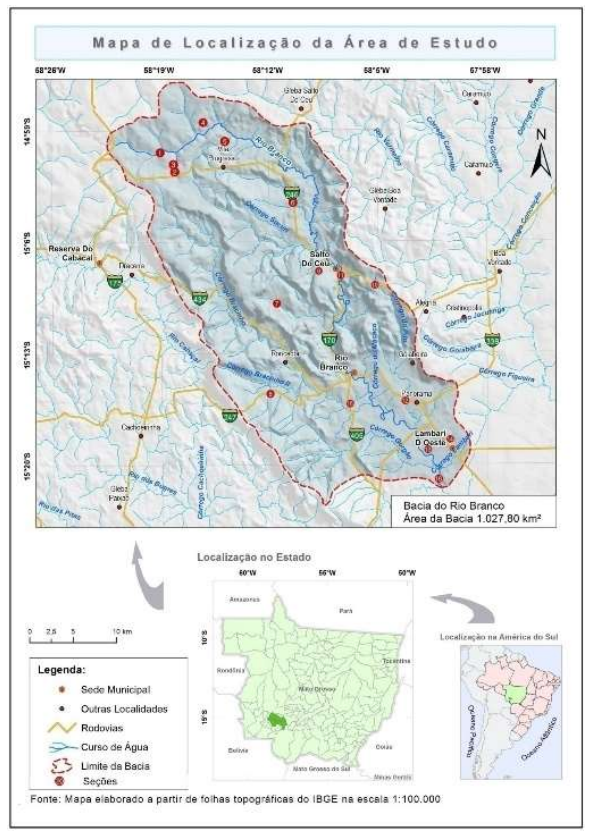

Figura 1: Mapa de localização e distribuição das seções na bacia do rio Branco. 


\section{METODOLOGIA}

A pesquisa foi realizada em três etapas: gabinete, campo e laboratório. A pesquisa bibliográfica compôs a etapa de gabinete. Foram realizadas leituras de obras sobre a temática, referentes à área de estudo.

Para calcular a área da seção, foi utilizada a fórmula A=P.L (onde $A$ é a área da seção, $P$ é a profundidade e $L$ é a largura do canal). Já para o cálculo da vazão, utilizou-se a fórmula $Q=A . V$ (onde $Q$ é a vazão, $A$ é a área e $V$ é a velocidade da água) (CUNHA, 2008).

Os valores de descarga sólida em suspensão (QSS) foram determinados pelo somatório do produto entre a concentração de sedimento suspenso da vertical (CSSi) e a respectiva descarga líquida da vertical (QI), na forma da expressão abaixo:

$$
Q_{s s} \equiv \Sigma\left(C_{s s} \cdot Q l_{i}\right) \cdot 0,0864
$$

Em que: Qss= descarga sólida em suspensão (t/dia-1); Css= concentração de sedimento em suspensão da vertical $\left(\mathrm{mg} / \mathrm{L}^{-1}\right) ; \mathrm{Q}_{\mathrm{i}}=$ descarga líquida da respectiva vertical $\left(\mathrm{m}^{3} / \mathrm{s}^{-1}\right)$ ( SOUZA et al., 2013).

\section{Trabalho em Campo}

A área de estudo foi dividida em dezesseis seções, sendo três no Rio Branco e treze nos afluentes (Figura 1). A pesquisa em campo foi realizada nos períodos de estiagem e no de chuvas, para observação, coleta de amostras de sedimentos (fundo e suspensão) e medição da velocidade do fluxo e da batimetria.

As amostras de sedimentos de fundo foram obtidas com auxílio de uma draga do tipo "Van Veen" (amostrador de mandíbulas). Os sedimentos em suspensão foram coletados na garrafa de "Van Dorn". Para medir a velocidade do fluxo, utilizou-se o molinete fluviométrico, sendo considerada apenas a medida de velocidade a $20 \%$ de profundidade.

\section{Análise dos Sedimentos em Suspensão}

Para análise dos sedimentos transportados em suspensão, foi usado o método de evaporação. As amostras de sedimentos em suspensão foram acondicionadas em béqueres pesados anteriormente. Realizou-se a secagem do material em estufa modelo TE-394/2. Os béqueres foram pesados três vezes com auxílio de balança analítica, definindo-se os valores de sedimentos em suspensão (mg/L) (CARVALHO et al., 2000).

Método da pipeta (dispersão total)

Para fracionamento do material de fundo em areia, silte e argila, utilizou-se o método da pipeta dispersão total (EMBRAPA, 1997).

\section{Método de peneiramento}

Para determinação do tamanho das partículas de sedimentos de fundo, foi adotado o método de peneiramento. A fração de areia separada pelo método de dispersão total foi seca em estufa a $105^{\circ} \mathrm{C}$. 
Posteriormente, o material foi submetido ao processo mecânico de peneiramento no agitador eletromagnético, com uma sequência de peneiras padronizadas, por 5 minutos. O material retido em cada uma das peneiras foi pesado separadamente e foram determinadas as frações de areia (grossa, média e fina) (SUGUIO, 1973).

\section{RESULTADOS E DISCUSSÃO}

O divisor de águas na bacia hidrográfica Rio Branco encontra-se em torno de 600 metros de altitude, enquanto a foz está a cerca de 150 metros. O rio principal e seus afluentes percorrem áreas de planaltos, apresentando fluxo turbulento com rupturas de declividade que originam corredeiras e cachoeiras. 0 gradiente contribui para ocorrência de vários níveis de base local, além de potencializar o transporte de materiais de fundo. As atividades humanas na bacia ocasionam diversos problemas ambientais, dentre eles os processos erosivos e o aumento da carga de sedimentos.

A dissecação do relevo propicia canais encaixados com morfologia bem definida em praticamente toda a rede de drenagem. Os canais apresentam dois padrões: retilíneos e meandros encaixados. Quanto à rede de drenagem, essa parte possui escoamento do tipo subparalelo.

As seções I, XI e XVI correspondem ao leito do Rio Branco (alto, médio e baixo curso). No alto curso (seção I), a vazão no período de estiagem foi de $0,626 \mathrm{~m}^{3} / \mathrm{s}$ e no chuvoso foi de $6,62 \mathrm{~m}^{3} / \mathrm{s}$. No médio curso (seção XI), a vazão no período de estiagem foi de $2,838 \mathrm{~m}^{3} / \mathrm{s}$ e no chuvoso foi de $42,30 \mathrm{~m}^{3} / \mathrm{s}$. No baixo curso (seção XVI), a vazão no período de estiagem foi de $4,861 \mathrm{~m}^{3} / \mathrm{s}$ e no chuvoso foi de $126,42 \mathrm{~m}^{3} / \mathrm{s}$ (figura 2 ).

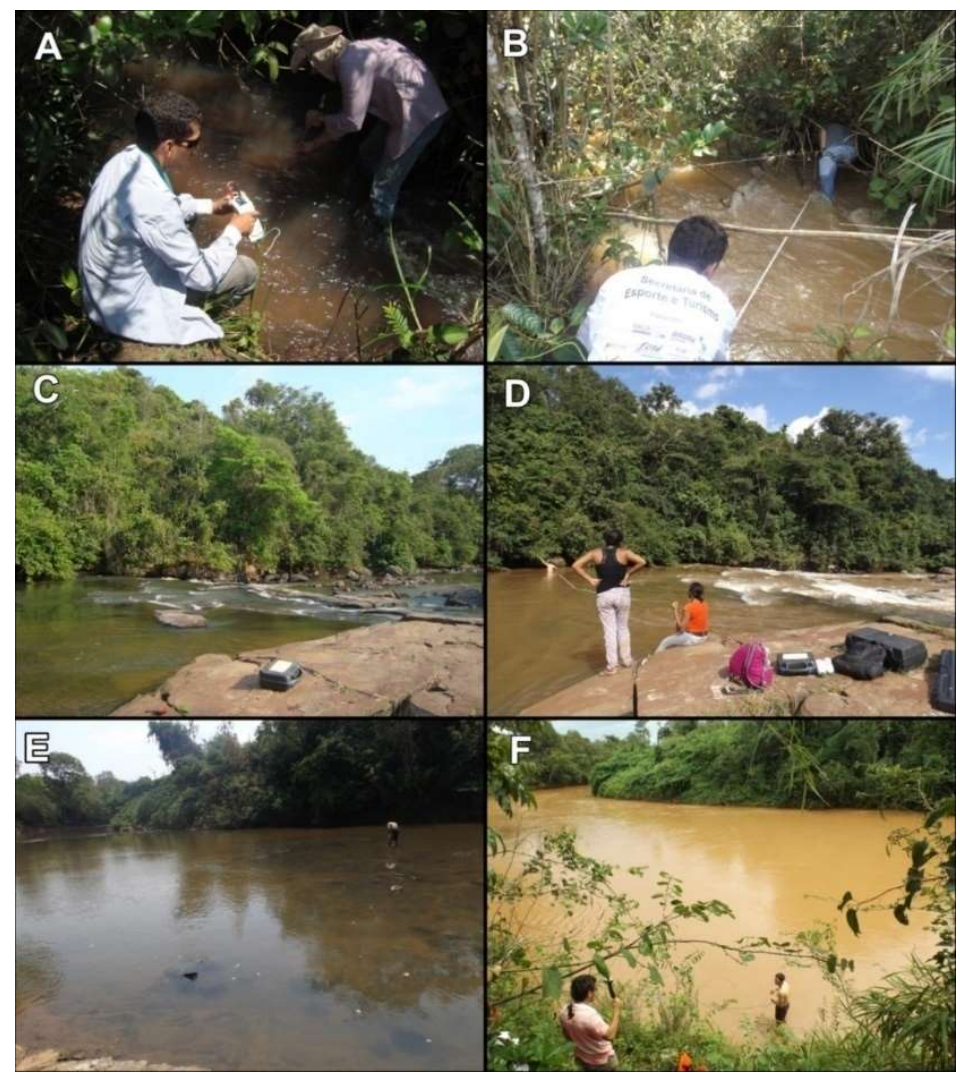

Figura 2: Seções no alto, médio e baixo curso do Rio Branco. Legenda: Seção I, no alto curso do Rio Branco, nos períodos de estiagem (A) e chuvoso (B). Seção XI, no médio curso do Rio Branco, estiagem (C) e chuvoso (D). Seção $X V I$, no baixo curso do Rio Branco, estiagem (E) e chuvoso (F). 
A bacia do Rio Branco demonstrou, no período chuvoso, uma capacidade de transporte de carga sólida em suspensão maior, comparando-se com o período de estiagem em todas as seções. A vazão apresentou elevação em todas as seções no período chuvoso. A turbidez, no período chuvoso, foi maior na maioria das seções, exceto nas seções II e VII. A carga de sedimentos suspensos apresentou-se maior no período de estiagem na maioria das seções (tabela 1).

Com as chuvas acontece a recarga do lençol freático elevando a vazão nos mananciais. As chuvas transportam grande quantidade de sedimentos para os canais de drenagem que em conjunto com a erosão marginal eleva as concentrações de sedimentos. A vazão elevada aumenta a turbulência do fluxo favorecendo a solução de sedimentos o que eleva a turbidez.

Tabela 01: Informações sobre a vazão, sedimentos em suspensão, turbidez e carga sólida em suspensão da BHRB.

\begin{tabular}{|c|c|c|c|c|c|c|c|c|c|}
\hline \multirow[t]{2}{*}{ Canal } & \multirow[b]{2}{*}{ S. } & \multicolumn{4}{|c|}{ Estiagem } & \multicolumn{4}{|c|}{ Chuvoso } \\
\hline & & V. $\mathrm{m}^{3} / \mathrm{s}$ & T. UTN & $\begin{array}{c}\mathrm{S} . S . \\
\mathrm{mg} / \mathrm{L}\end{array}$ & $\begin{array}{c}\text { Qss } \\
\text { t/dia-1 }\end{array}$ & V. $\mathrm{m}^{3} / \mathrm{s}$ & T. UTN & S.S. $\mathrm{mg} / \mathrm{L}$ & $\begin{array}{c}\text { Qss } \\
\text { t/dia-1 }\end{array}$ \\
\hline Rio Branco (prox. à nascente) & I & 0,626 & 8,88 & 40 & 2,16 & 6,62 & 47,7 & 44 & 25,2 \\
\hline Córrego Quatorze antes da voçoroca & II & 0,017 & 2,23 & 30 & 0,04 & 0,195 & 2,1 & 12 & 0,2 \\
\hline Córrego Quatorze depois da voçoroca & III & 0,034 & 50,6 & 280 & 0,82 & 0,247 & 153 & 112 & 2,39 \\
\hline Córrego Fazenda Lalau & IV & 0,012 & 10,2 & 40 & 0,04 & 0,11 & 9,22 & 30 & 0,29 \\
\hline Córrego Santa Virginia & $\mathbf{V}$ & 0,456 & 5,23 & 40 & 1,58 & 7,37 & 27,6 & 34 & 21,7 \\
\hline Córrego Rio Negro & VI & 0,238 & 3,25 & 80 & 1,65 & 4,19 & 23,7 & 50 & 18,1 \\
\hline Córrego das Pedras & VII & 0,056 & 7,91 & 30 & 0,15 & 2,184 & 9,67 & 26 & 4,91 \\
\hline Córrego Bracinho 3 & VIII & 0,04 & 5,16 & 40 & 0,14 & 1,28 & 3,01 & 14 & 1,55 \\
\hline Córrego da Onça & IX & 0,005 & 5,94 & 40 & 0,02 & 0,7 & 12,5 & 32 & 1,94 \\
\hline Córrego do Pito (montante) & $x$ & 0,036 & 5,79 & 80 & 0,25 & 0,43 & 11,05 & 30 & 1,11 \\
\hline Rio Branco & $\mathbf{X I}$ & 2,838 & 8,37 & 60 & 14,7 & 42,3 & 85,5 & 42 & 153 \\
\hline Córrego do Pito (jusante) & XII & 0,856 & 9,77 & 60 & 4,44 & 12,19 & 22 & 76 & 80 \\
\hline Córrego São Pedro & XIII & 0,085 & 11,09 & 80 & 0,59 & 2,04 & 16,1 & 62 & 10,9 \\
\hline Córrego Lambari & XIV & 0,043 & 5,39 & 20 & 0,07 & 0,45 & 13,1 & 28 & 1,09 \\
\hline Córrego Bracinho & XV & 1,976 & 7,99 & 60 & 10,2 & 35,07 & 363 & 252 & 764 \\
\hline Rio Branco & XVI & 4,861 & 12,85 & 60 & 25,2 & 126,42 & 420 & 288 & 3146 \\
\hline
\end{tabular}

Legenda: S: seção; V: velocidade; T: turbidez; S.S: sedimento em suspensão; Qss: carga sólida em suspensão.

No período de estiagem, os sedimentos transportados em suspensão no canal principal registraram $40 \mathrm{mg} / \mathrm{L}$ no alto curso (seção I) e 60mg/L nos cursos médio e baixo (seções XI e XVI respectivamente). No período chuvoso, os sedimentos em suspensão foram de $44 \mathrm{mg} / \mathrm{L}$ no alto curso, de $42 \mathrm{mg} / \mathrm{L}$ no médio curso e de $288 \mathrm{mg} / \mathrm{L}$ no baixo curso. A elevação nos sedimentos em suspensão no baixo curso está relacionada à carga de sedimentos transportados pelos afluentes, com destaque para o Córrego Bracinho (tabela 01).

A turbidez no canal principal no período de estiagem foi de 8,88 UTN no alto curso, de 8,37 UTN no médio curso e de 12,85 UTN no baixo curso. No período chuvoso, a turbidez foi de 47,7 UTN alto curso, de 85,5 UTN no médio curso e de 420 UTN no baixo curso.

A carga sólida em suspensão no Rio Branco, durante o período de estiagem, foi de 2,16 t/dia-1 no alto curso, de 14,7 t/dia ${ }^{-1}$ no médio curso e de 126,42 t/dia-1 no baixo curso. No período chuvoso, a carga sólida em suspensão foi de $25,2 \mathrm{t} / \mathrm{dia}^{-1}$ no alto curso, de $153 \mathrm{t} / \mathrm{dia}^{-1}$ no médio curso e de $3.146 \mathrm{t} / \mathrm{dia}^{-1}$ no baixo curso.

As informações sobre a composição granulométrica de sedimentos de fundo obtidas mostraram a predominância das frações de areia, com destaque a areia fina (tabela 2). Nas atividades de campo, observouse a presença de afloramentos rochosos, fragmentos de rochas, matacões e seixos no leito. Esse material está associado à litologia e aos processos erosivos associados ao uso da terra na bacia. Os sedimentos 
encontrados têm origem em na litologia da bacia hidrográfica do Rio Branco. Os manejos dos diversos tipos de solos impactam diretamente a hidrodinâmica e a sedimentação da bacia.

Tabela 2: Composição granulométrica dos sedimentos de fundo na BHRB.

\begin{tabular}{c|c|c|c|c|c|c|c|c|c|c}
\hline & \multicolumn{9}{|c|}{ Estiagem } & \multicolumn{3}{c}{ Chuvoso } \\
\hline S. & $\begin{array}{c}\text { A. G. } \\
\%\end{array}$ & A. M. \% & A. F. \% & $\begin{array}{c}\text { Silte } \\
\%\end{array}$ & $\begin{array}{c}\text { Arg. } \\
\%\end{array}$ & A. G.\% & A. M. \% & A. F. \% & $\begin{array}{c}\text { Silte } \\
\%\end{array}$ & $\begin{array}{c}\text { Arg. } \\
\%\end{array}$ \\
I & - & - & - & - & - & - & - & - & - & - \\
II & 27,8 & 25 & 45,95 & 0,8 & 0,45 & 47,90 & 5,75 & 44,95 & 1,03 & 0,37 \\
III & 0 & 0,43 & 98,5 & 0,65 & 0,42 & - & 0,25 & 98,4 & 1,03 & 0,32 \\
IV & 0,05 & 0,08 & 97,7 & 1,77 & 0,4 & 3,85 & 1,55 & 93,45 & 0,83 & 0,32 \\
V & 0,15 & 0,4 & 99,05 & 0,05 & 0,35 & 2,25 & 2,65 & 94,6 & 0,18 & 0,32 \\
VI & 16,4 & 33 & 50,15 & 0,15 & 0,35 & 29,00 & 54,2 & 15,35 & 1,18 & 0,27 \\
VII & 52,95 & 20,9 & 22,2 & 3,4 & 0,55 & 22,45 & 40,2 & 34,7 & 2,25 & 0,45 \\
VIII & 24,95 & 9,0 & 62,7 & 2,7 & 0,65 & 1,95 & 9,05 & 86,45 & 2,13 & 0,42 \\
IX & 36,95 & 28,2 & 27,25 & 7,07 & 0,55 & 22,70 & 26,7 & 46,25 & 3,95 & 0,45 \\
X & 11,1 & 8,75 & 72,15 & 7,25 & 0,75 & 64,10 & 14,4 & 18,75 & 2,33 & 0,42 \\
XI & 11,45 & 19,1 & 68,85 & 0,25 & 0,35 & 11,85 & 1,9 & 83,55 & 2,25 & 0,45 \\
XII & 1,8 & 17,6 & 76,9 & 3,35 & 0,35 & - & 29,2 & 68,9 & 1,55 & 0,4 \\
XIII & 9,25 & 18,1 & 69,65 & 2,65 & 0,4 & 9,40 & 22,9 & 50,25 & 16,65 & 0,8 \\
XIV & 45,92 & 14,9 & 28,5 & 9,88 & 0,85 & 66,63 & 11,8 & 13,2 & 7,83 & 0,57 \\
XV & 3,12 & 23,7 & 71,8 & 0,93 & 0,45 & - & 3,05 & 94,6 & 1,9 & 0,45 \\
XVI & 8,88 & 10,32 & 76,92 & 3,4 & 0,48 & - & - & - & - & - \\
\hline
\end{tabular}

Legenda: S: seção, Arg: Argila, A.G: areia grossa, A.M: areia média, A.F: areia fina.

No período de estiagem, a maioria dos canais apresenta débitos reduzidos, que limitam sua capacidade de transporte de materiais mais grosseiros; porém, no período chuvoso, o fluxo aumenta significativamente com a declividade do terreno, que potencializa essa capacidade, como é possível observar, pela grande quantidade de fragmentos de rochas de diversas dimensões encontradas nos leitos.

Ao fazer a análise sedimentológica do alto curso da bacia hidrográfica do Córrego Cachoeirinha, Santos et al. (2013) concluíram que a capacidade de transporte de sedimentos está tão associada ao volume de água no canal (potencializado no período de cheia) que pode causar até mesmo a fragmentação de rochas de arenito depositadas em seu leito, bem como ao relevo que, caso seja acidentado, causa maior turbulência no fluxo. Isso pode favorecer o transporte de sedimentos em suspensão e facilitar o transporte de sedimento de fundo, inclusive de materiais mais grosseiros.

\section{Afluentes do Rio Branco}

\section{Córrego Quatorze}

O Córrego Quatorze possui em torno de $5 \mathrm{~km}$ de extensão. Nasce na serra do Roncador - Salto do Céu, no Planalto Dissecado dos Parecis, com ocorrência da Formação Utiariti do Grupo Parecis. Sua nascente encontra-se a 580 m de altitude, deságua na margem direita do Rio Branco. O tipo de canal enquadra-se na classificação elaborada por Christofoletti (1981) como sinuoso, que são canais transacionais entre retos e meandrante.

A cobertura pedológica encontrada na área onde se encontra o Córrego Quatorze é Neossolo Quartzarênico Órtico típico. Por ser um solo jovem é pouco evoluído, possui fragilidade ao intemperismo e detém textura arenosa. Esse tipo de solo necessita de manejos adequados devido a sua fragilidade, a falta 
de adoção de medidas conservacionistas levou ao surgimento de voçorocas como a encontrada na sub-bacia do Córrego Quatorze.

Para verificar a influência da voçoroca na sedimentologia do Córrego Quatorze, foram definidas duas seções nesse córrego, sendo uma a montante da voçoroca (seção II) e outra a jusante (seção III). A voçoroca presente na sub-bacia do Córrego Quatorze ocupa uma área de $0,048 \mathrm{~km}^{2}$, possui cerca de 450 metros de comprimento e atinge cerca de 20 metros de profundidade (figura 3 ).

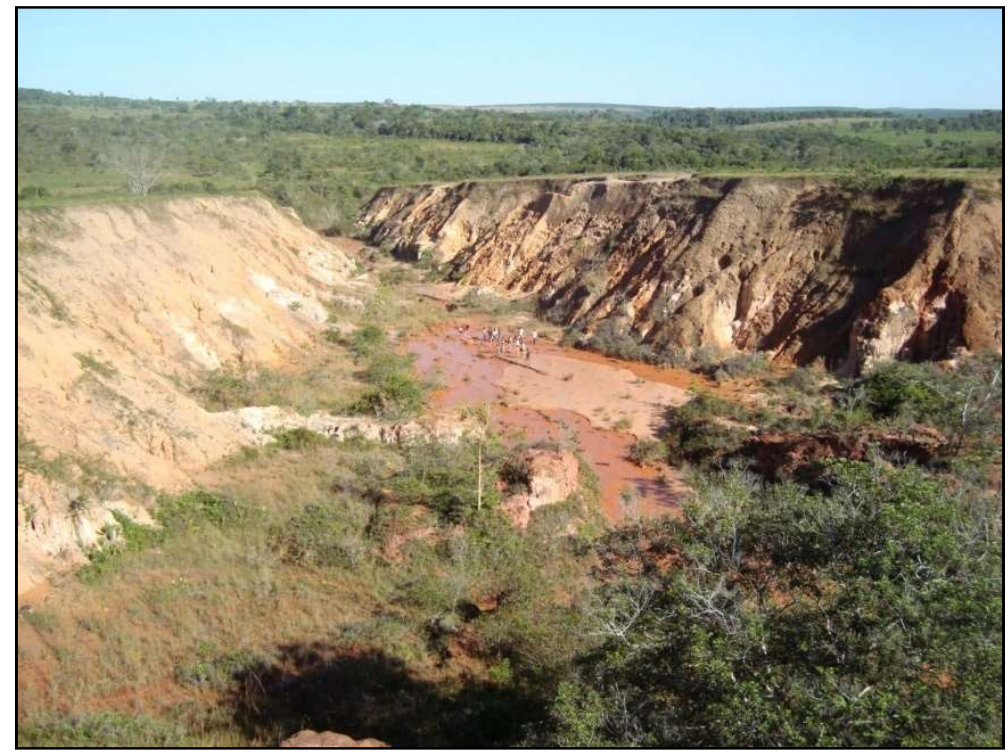

Figura 3: Voçoroca na sub-bacia do Córrego Quatorze.

No período de estiagem, a seção II registrou a concentração de sedimentos suspensos de $30 \mathrm{mg} / \mathrm{L}$; já a seção III mostrou a concentração de $280 \mathrm{mg} / \mathrm{L}$. No período chuvoso, na seção II foi registrado $12 \mathrm{mg} / \mathrm{L}$; na seção II detectou-se112ml/L. A carga sólida em suspensão no período de estiagem na seção II foi de 0,04 $\mathrm{t} / \mathrm{dia}^{-1}$ e na seção III de $0,82 \mathrm{t} / \mathrm{dia}^{-1}$. No período chuvoso, a carga sólida suspensa foi de $0,2 \mathrm{t} / \mathrm{dia}^{-1}$, na seção II, e de 2,39 t/dia-1 na seção III. Nos dois períodos, foi registrado maior volume de carga de sedimento suspenso na seção III, mostrando a fragilidade do solo Neossolo Quartzarênico e a influência dos processos erosivos no aumento na carga de sedimentos.

A turbidez no período de estiagem ficou em 2,23 UTN na seção II e em 50,6 UTN na seção III. No período chuvoso, a turbidez na seção II foi de 2,1 UTN; na seção III, foi de 153 UTN. O aumento da concentração de sedimentos transportados em suspensão na seção III está relacionado ao processo erosivo (voçoroca) próximo do curso de água, elevando também a turbidez do Córrego Quatorze (tabela 1).

A influência da voçoroca sobre a dinâmica fluvial do Córrego Quatorze pode ser verificada pelas seções feitas a montante e a jusante da voçoroca nos períodos de estiagem e chuvoso.

A chegada do fluxo oriundo da voçoroca no Córrego Quatorze altera completamente suas características, ocasionando o aumento da turbidez, da carga de sedimentos suspensos e da composição dos sedimentos de fundo. Como pode ser observado na figura 4, o Córrego Quatorze, a montante da voçoroca, possui água límpida, com presença de sedimentos grosseiros no fundo. Já a jusante da voçoroca, o canal aumenta a turbidez e os sedimentos de fundo passam ser construídos principalmente de areia fina. 


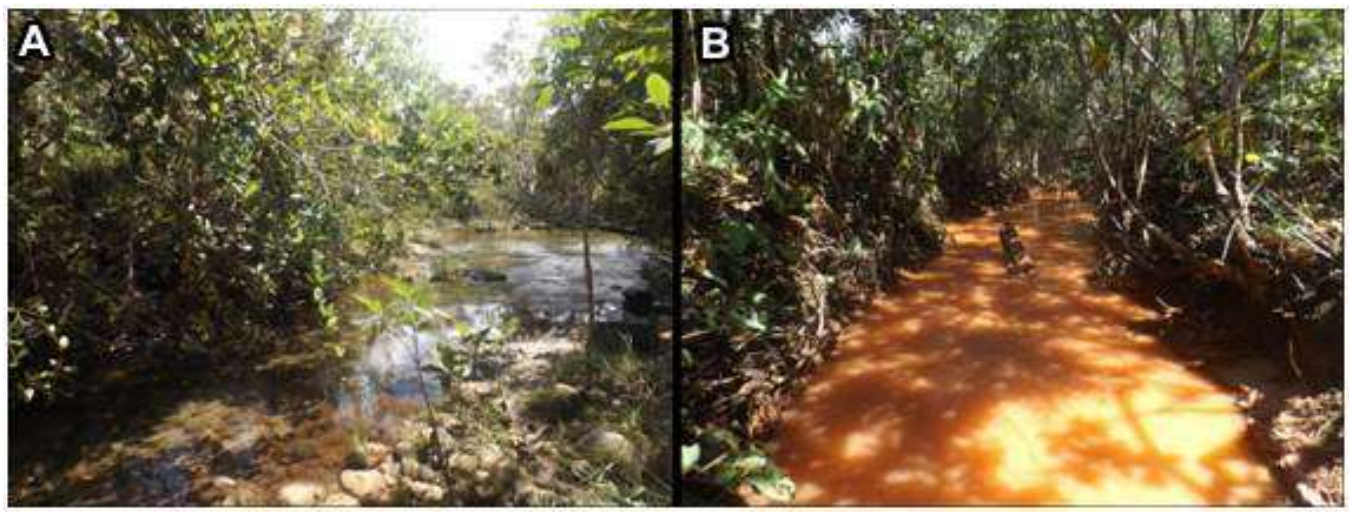

Figura 4: Córrego Quatorze antes (A) e depois da voçoroca (B).

Quanto à composição granulométrica dos sedimentos de fundo, predominou areia, distribuída na maioria entre areia grossa e areia fina. A porção de areia grossa na seção II foi encontrada em maior quantidade no período chuvoso. Esse fato demonstra um aumento da capacidade de transporte de sedimentos no período chuvoso. Na seção III predominou areia fina em cerca de $98 \%$ nos dois períodos (tabela 2).

\section{Córrego Fazenda Lalau}

O Córrego Fazenda Lalau possui cerca de 1 km de extensão e apresenta-se sinuoso. Nasce no Planalto dos Parecis, na Formação Utiariti e sua nascente encontra-se a $541 \mathrm{~m}$ de altitude, desaguando na margem esquerda do Rio Branco, com uso para pastagens.

No período de estiagem, a seção IV registrou a concentração de sedimentos suspensos de $40 \mathrm{mg} / \mathrm{L}$. No período chuvoso, foram detectados $30 \mathrm{mg} / \mathrm{L}$. A turbidez no período de estiagem ficou em 10,2 UTN. No período chuvoso, a turbidez foi de 9,22 UTN. A carga sólida suspensa foi de 0,04 t/dia ${ }^{-1}$ no período de estiagem e de $0,29 \mathrm{t} / \mathrm{dia}^{-1}$ no período chuvoso. Nos sedimentos de fundo, prevaleceu a fração de areia fina nos dois períodos (tabelas 1 e 2).

A cobertura pedológica na sub-bacia é do Neossolo Quartzarênico Órtico típico, a seção está localizada em uma área de pouco caimento topográfico que contribui para uma menor velocidade do fluxo principalmente no período de estiagem. A falta de velocidade no fluxo e a baixa vazão podem estar associadas a uma maior concentração de sedimentos em suspensão no período de estiagem, pois dificulta a saída dos mesmos do sistema.

\section{Córrego Santa Virginia}

O Córrego Santa Virginia possui cerca de 17 km de extensão. Nasce da serra do Roncador - Salto do Céu tem ocorrência da Formação Morro Cristalino no alto curso e da Formação Vale da Promissão no baixo curso. Sua nascente situa-se a cerca de 630 metros de altitude, desaguando na margem esquerda do Rio Branco.

O vale apresenta-se em forma de $U$ e nas escarpas são encontradas diversas nascentes que compõem uma rede de drenagem paralela que converge para o canal principal dessa sub-bacia. O tipo de canal é 
sinuoso, sendo transacional entre reto e meandrante. $\mathrm{O}$ uso designa-se a pastagens, no leito possui areia. $\mathrm{Na}$ sua bacia há presença de duas grandes voçorocas que provocam intenso assoreamento de seu leito.

No período de estiagem, a seção $V$ registrou a concentração de sedimentos suspensos de $40 \mathrm{mg} / \mathrm{L}$. No período chuvoso foi registrado $34 \mathrm{mg} / \mathrm{L}$. A turbidez no período de estiagem ficou em 5,23 UTN. No período chuvoso, a turbidez foi de 27,6 UTN. A carga sólida suspensa foi de $1,58 \mathrm{t} / \mathrm{dia}^{-1}$ no período de estiagem e de $21,7 \mathrm{t} / \mathrm{dia}^{-1}$ no período chuvoso (tabela 1 ).

Quanto aos sedimentos de fundo, no período de estiagem prevaleceu a porção areia fina $(99,05 \%)$,que, em grande parte, tem origem nas duas voçorocas que acarreiam seus sedimentos para o Córrego Santa Virginia. No período chuvoso, houve um aumento nas frações de areia grossa e média; entretanto, a fração areia fina continuou a prevalecer com 94,6\% (tabela 2).

Na sub-bacia do Córrego Santa Virginia são encontrados os solos Neossolo Quartzarênico Órtico típico e o Nitossolo Vermelho Distroférrico típico respectivamente, sendo a cobertura maior a do Neossolo. Os sedimentos em suspensão e a areia fina oriundos das voçorocas ficam em concentrações maiores no período de estiagem quando a vazão do córrego é menor. Com o aumento da vazão os sedimentos dos processos erosivos ocupam menor fração do volume do córrego e assim são reduzidos.

\section{Córrego Rio Negro}

O Córrego Rio Negro possui cerca de 20 km de extensão. Nasce da serra do Roncador-Salto do Céu, com ocorrência da Formação Morro Cristalino no alto curso, da Formação Vale da Promissão no médio curso e do Grupo Rio Branco no baixo curso. Sua nascente encontra-se a 568m de altitude, deságua na margem direita do Rio Branco a uma altitude de 337 metros; seu uso é para pastagens. Sua drenagem alterna entre os tipos sinuoso no alto curso e meandrante nos cursos médio e baixo. Observou-se a presença de seixos rolados e fragmentos de rochas.

No período de estiagem, na seção $\mathrm{VI}$, detectou-se a concentração de sedimentos suspensos de $80 \mathrm{mg} / \mathrm{L}$. No período chuvoso foi registrado $50 \mathrm{mg} / \mathrm{L}$. A turbidez, no período de estiagem, ficou em 3,25 UTN. No período chuvoso, a turbidez foi de 23,7 UTN. A carga sólida suspensa foi de 1,65 t/dia ${ }^{-1}$ no período de estiagem e de $18,1 \mathrm{t} / \mathrm{dia}^{-1}$ no período chuvoso. No período chuvoso, houve aumento na turbidez, a carga de sedimentos suspensos reduziu; mas, com aumento da vazão, elevou-se a carga sólida em suspensão (tabela 1). O Córrego Rio Negro está sob cobertura pedológica do Nitossolo Vermelho Distroférrico típico.

Entre os sedimentos de fundo, prevaleceu a fração de areia fina $(50,15 \%)$ no período de estiagem. No período chuvoso foi encontrada em maior quantidade a fração de areia média (54,2\%). Esse aumento na granulometria pode ser justificado pela elevação da vazão que aumenta a capacidade de transporte de sedimentos mais grosseiros (tabela 2).

\section{Córrego das Pedras}

O Córrego das Pedras possui 13 km de extensão. Nasce na serra Roncador-Salto do Céu e deságua na margem direita do Rio Branco, na Depressão do Alto Paraguai, com ocorrência da Formação Morro 
Cristalino no Alto Curso e da Formação Vale da Promissão no baixo curso. Sua nascente encontra-se a $480 \mathrm{~m}$ de altitude e a sua foz a 202 metros. O entorno é usado para pastagens. Na sua área de nascente é encontrado o Neossolo Litólico Distrófico fragmentário e transcorre sob a cobertura pedológica do Latossolo Vermelho Distrófico argissólico.

O leito é encaixado com presença de material grosseiro, como seixos rolados e fragmentos de rochas (Figura 9). O fluxo apresenta corredeiras, reflexo da declividade acentuada, apresentando $21,38 \mathrm{~m} / \mathrm{km}$. São encontrados diversos afloramentos de arenito, que muitas vezes alteram o nível de base, originando diversas quedas d'água.

Na seção VII, no período de estiagem, registrou-se a concentração de sedimentos suspensos de $30 \mathrm{mg} / \mathrm{L}$; no período chuvoso, $26 \mathrm{mg} / \mathrm{L}$. A turbidez no período de estiagem ficou em 7,91 UTN; no período chuvoso, 9,67 UTN. A carga sólida suspensa foi de $0,15 \mathrm{t} / \mathrm{dia}^{-1}$ no período de estiagem e de 4,91 t/dia-1 no período chuvoso. A concentração de sedimentos suspensos diminuiu no período chuvoso; porém, com a elevação da vazão, a carga sólida de sedimentos suspensos elevou-se assim como a turbidez (tabela 1).

$\mathrm{Na}$ composição granulométrica dos sedimentos de fundo, houve a prevalência de areia grossa (52,95\%) no período de estiagem e de areia média $(40,2 \%)$ no período chuvoso (tabela 2 ).

\section{Córrego Bracinho III}

O Córrego Bracinho III possui cerca de 4,9 km de extensão e apresenta canal retilíneo em alguns trechos e sinuoso na maior parte do percurso. Nasce na serra do Roncador-Salto do Céu, com ocorrência da Formação Fortuna. Sua nascente situa-se a $475 \mathrm{~m}$ de altitude, deságua na margem direita do Córrego Bracinho II a uma altitude de $263 \mathrm{~m}$, o uso destina-se a pastagens.

No período de estiagem, o fluxo na seção apresentou-se suave com velocidade reduzida. No período chuvoso, houve elevação da vazão, o que aumentou a turbulência do fluxo devido à rugosidade do leito e à declividade do canal. No período de estiagem, o alto curso do canal é intermitente e aflora em rocha de arenito a montante da seção. Ocorrem vários afloramentos de arenito nas partes mais elevadas do relevo, o qual possui como cobertura pedológica o Neossolo Litólico Distrófico fragmentário.

A concentração de sedimentos suspensos na seção VIII, no período de estiagem, foi de $40 \mathrm{mg} / \mathrm{L}$. No período chuvoso, registrou-se $14 \mathrm{mg} / \mathrm{L}$. A turbidez no período de estiagem ficou em 5,16 UTN. No período chuvoso, a turbidez foi de 3,01 UTN. A carga sólida suspensa foi de $0,14 \mathrm{t} / \mathrm{dia}^{-1}$ no período de estiagem e de $1,55 \mathrm{t} / \mathrm{dia}^{-1}$ no período chuvoso. A turbidez e a carga de sedimentos suspensos diminuíram no período chuvoso com o aumento da vazão, o qual, porém, proporcionou a elevação carga sólida suspensa (tabela 1).

Nos sedimentos de fundo, a fração areia fina predominou nos dois períodos, registrando $62,7 \%$ no período de estiagem e $86,45 \%$ no período chuvoso. A fração de areia grossa foi encontrada em maior proporção no período de estiagem (tabela 2). 


\section{Córrego da Onça}

O Córrego da Onça possui $4.1 \mathrm{~km}$ de extensão, com trechos retilíneos e sinuosos. Nasce na serra do Roncador-Salto do Céu, com ocorrência da Formação Morro Cristalino no alto curso e da Formação Vale da Promissão no baixo curso. Sua nascente encontra-se a 430 metros de altitude e a foz a 316 metros, desaguando na margem direita do Rio Branco; o uso dessa sub-bacia destina-se a pastagens.

Nessa seção, foi observada a presença de erosão marginal e de acúmulo de material de construção. A rugosidade do leito favorece a turbulência do fluxo, principalmente no período chuvoso, quando a vazão aumenta. Observou-se a presença de sedimentos grosseiros (Figura 11). O Córrego da Onça está situado sob cobertura pedológica do Cambissolo Háplico Alumínico, no leito é encontrado diversos fragmentos das rochas que compreendem o material de origem desse solo.

A concentração de sedimentos suspensos na seção IX foi de $40 \mathrm{mg} / \mathrm{L}$ no período de estiagem e de $32 \mathrm{mg} / \mathrm{L}$ no período chuvoso. A turbidez, que no período de estiagem registrou 5,94 UTN, apresentou um aumento durante o período chuvoso, alcançando 12,5 UTN. A carga sólida suspensa foi de $0,02 \mathrm{t} / \mathrm{dia}^{-1}$ no período de estiagem e de $1,94 \mathrm{t} / \mathrm{dia}^{-1}$ no período chuvoso. Nos sedimentos de fundo, prevaleceu a fração areia grossa, com $36,95 \%$ no período de estiagem; e de areia fina, com $46,25 \%$ no período chuvoso (tabelas 1 e 2).

\section{Córrego do Pito}

O Córrego do Pito possui $24,30 \mathrm{~km}$ de extensão, alguns trechos retilíneos e outros sinuosos. Nasce na serra do Roncador-Salto do Céu a 491m de altitude e deságua na margem esquerda do Rio Branco, a 163 m. O córrego percorre a litologia da Formação Vale da Promissão e do Grupo Rio Branco. O uso do entorno é destinado à pastagem. Nasce sob o Argissolo Vermelho-amarelo Distrófico típico, passando pelo Cambissolo Háplico Tb Distrófico léptico e Latossolo Vermelho Distrófico argissólico onde está sua foz.

Na seção X que está próxima à nascente, o fluxo possui velocidade reduzida nos dois períodos, sendo encontradas no leito apenas frações de areia. Na seção XII que está próxima à foz, a vazão eleva-se e o leito rugoso, devido aos fragmentos de rochas e seixos rolados, faz aumentar a turbulência do fluxo. Observou-se a presença de seixos rolados e de fragmentos de rochas.

A concentração de sedimentos suspensos no período de estiagem nas seções X e XII foram de $80 \mathrm{mg} / \mathrm{L}$ e $60 \mathrm{mg} / \mathrm{L}$ respectivamente. No período chuvoso, foram registrados $30 \mathrm{mg} / \mathrm{L}$ na seção $X$ e $76 \mathrm{mg} / \mathrm{L}$ na seção XII. A turbidez no período de estiagem ficou em 5,79 UTN na seção X e 9,77 UTN na seção XII. No período chuvoso, a turbidez nas seções X e XII foram de 11,5 UTN e 22 UTN, respectivamente. A carga sólida suspensa na seção $X$ foi de $0,25 \mathrm{t} /$ dia $^{-1}$ na estiagem e de $1,11 \mathrm{t} /$ dia $^{-1}$ no período chuvoso. Já na seção XII os valores foram $4,44 \mathrm{t} / \mathrm{dia}^{-1} \mathrm{e}$ de $80 \mathrm{t} / \mathrm{dia}^{-1}$ nos períodos de estiagem e chuvoso respectivamente (tabela 1 ).

Entre os sedimentos de fundo, houve a prevalência da fração de areia fina nas duas seções. No período chuvoso, na seção X, prevaleceu a fração de areia grossa; na seção XII predominou areia fina (tabela 2). 


\section{Córrego São Pedro}

O Córrego São Pedro possui 3,41km de extensão e apresenta um canal do tipo meandrante. Nasce na Depressão do Alto Paraguai, a 202 metros de altitude, e deságua na margem esquerda do Rio Branco, nas Planícies Fluviais, a 158 metros de altitude. O córrego percorre os sedimentos da Formação Pantanal e Aluviões. O uso destina-se a pastagens e à agricultura (cana-de-açúcar). A cobertura pedológica corresponde ao Latossolo Vermelho Distrófico argissólico e ao Gleissolo Háplico Alumínico típico.

Possui mata ciliar em toda a sua extensão, o que contribui pra a estabilidade de suas margens e proteção do canal quanto aos sedimentos oriundos dos terrenos adjacentes. Nas margens, há presença de raízes de árvores que contribuem para sua estabilidade. No leito, são encontrados restos vegetais, tais como galhos e folhas, principalmente no período de estiagem, quando a velocidade é reduzida. Como o gradiente é suave, não é comum a presença de seixos rolados e de fragmentos de rochas, o que demonstra que o canal não possui competência para transportar materiais mais pesados.

A vazão no Córrego São Pedro no período de estiagem foi de $0,085 \mathrm{~m}^{3} / \mathrm{s}$; no período chuvoso, esse item aumentou para $2,041 \mathrm{~m}^{3} / \mathrm{s}$. A carga de sedimentos suspensos foi de $80 \mathrm{mg} / \mathrm{L}$ no período de estiagem, reduzindo para $62 \mathrm{mg} / \mathrm{L}$ no período chuvoso. A turbidez, que no período de estiagem foi de 11,09 UTN, elevou-se para 16,1 UTN no período chuvoso. A carga sólida suspensa apresentou 0,59 t/dia-1 no período de estiagem e 10,9 t/dia ${ }^{-1}$ no período chuvoso. Na granulometria dos sedimentos de fundo, prevaleceu a fração areia fina nos dois períodos, com aumento de areia média no período chuvoso (tabelas 1 e 2 ).

\section{Córrego Lambari}

O Córrego Lambari possui 5,6 km de extensão e padrão meandrante. Nasce na Depressão do Alto Paraguai, a 201 m de altitude; percorre sobre a litologia da Formação Pantanal e da Formação Vale da Promissão no baixo curso. Seu uso destina-se a pastagens e ao cultivo de cana-de-açúcar. A cobertura pedológica corresponde ao Latossolo Vermelho Distrófico argissólico.

O córrego corta o centro urbano de Lambari D'Oeste, onde sofre um represamento, fato que, segundo Christofoletti (1981), favorece a deposição tanto dos sedimentos de fundos quanto dos de suspensão. A seção XIV localiza-se a montante do barramento, onde as características do canal encontramse relativamente preservadas.

A vazão no Córrego Lambari no período de estiagem foi de $0,043 \mathrm{~m}^{3} / \mathrm{s}$, elevando-se para $0,45 \mathrm{~m}^{3} / \mathrm{s}$ no período chuvoso. A turbidez, que no período de estiagem foi de 5,39 UTN, aumentou para 13,1 UTN no período chuvoso. A carga de sedimentos em suspensão registrou $20 \mathrm{mg} / \mathrm{L}$ no período de estiagem e $28 \mathrm{mg} / \mathrm{L}$ no período chuvoso. A carga sólida suspensa registrou $0,07 \mathrm{t} / \mathrm{dia}^{-1}$ no período de estiagem e 1,09 t/dia ${ }^{-1}$ no período chuvoso. Na composição granulométrica dos sedimentos de fundo, prevaleceu a fração de areia grossa nos dois períodos, sendo $45,92 \%$ na estiagem e $66,63 \%$ no chuvoso (tabelas 1 e 2 ). 


\section{Córrego Bracinho}

O Córrego Bracinho possui 51,19 km de extensão. Nasce na serra do Roncador-Salto do Céu, a 650 m de altitude, e deságua na margem direita do Rio Branco, na Depressão do Alto Paraguai. O córrego percorre a litologia das formações Utiariti, Fortuna e Vale da Promissão. No Córrego Bracinho, a alguns metros da montante da seção, é coletada a água destinada ao abastecimento residencial da cidade de Rio Branco.

De todos os afluentes do Rio Branco o Córrego Bracinho é o que apresenta maiores diversidades litológicas, pedológicas e geomorfológicas. Sua nascente está sob o Neossolo Quartzarênico Órtico típico, logo a jusante passa por cobertura pedológica do Neossolo Litólico Distrófico fragmentário por um pequeno trecho e depois predomina o Latossolo Vermelho Distrófico argissólico.

O Córrego Bracinho apresenta vários afluentes, tendo a maioria deles suas nascentes no MP-VI. Possui padrão de drenagem subparalelo do tipo sinuoso. A maior parte de seus afluentes ocupa sua margem direita e nascem nas vertentes da Serra de Monte Cristo, no Planalto Dissecado dos Parecis. A declividade na maioria dos casos é elevada, o que favorece a velocidade do fluxo principalmente durante as cheias e permite ao córrego transportar sedimentos grosseiros (Figura 15).

Os fragmentos de rochas deixam os leitos rugosos, o que ocasiona maior turbulência no fluxo, principalmente no período chuvoso. Nos canais que compõem a bacia do Córrego Bracinho, existem diversos afloramentos de arenito que alteram o nível de base e dão origem a diversas corredeiras e quedas d'água, as mais conhecidas são as Cachoeiras do Roncador, Poço Azul e Paraíso I, II e III. Seu uso destina-se a pastagens para a prática da pecuária.

O Córrego Bracinho, principal afluente do Rio Branco, possui sua área de abrangência muito degradada, suas matas ciliares são praticamente inexistentes e suas nascentes estão quase sempre desprotegidas. Sendo assim, no período de estiagem, sua vazão fica reduzida, registrando-se 1,976 m³/s. A vazão no período chuvoso foi $35,07 \mathrm{~m}^{3} / \mathrm{s}$. A capacidade de transporte de sedimentos suspensos aumentou de $60 \mathrm{mg} / \mathrm{L}$, no período de estiagem, para $288 \mathrm{ml} / \mathrm{L}$ no período chuvoso. A turbidez elevou-se de 7,99 UTN para 363 UTN entre os períodos de estiagem e chuvoso. A carga sólida suspensa foi de $10,2 \mathrm{t} / \mathrm{dia}^{-1}$ no período de estiagem e de $764 \mathrm{t} / \mathrm{dia}^{-1}$ no período chuvoso. Na composição granulométrica dos sedimentos de fundo, houve a prevalência da fração de areia fina, que aumentou no período chuvoso (tabelas 1 e 2).

Na bacia do Córrego Bracinho, o intenso uso e a falta de proteção das matas ciliares estão aumentando o escoamento superficial, que ocasionam cheias e aumentam a carga de sedimentos transportados tanto de fundo como de suspensão.

\section{CONCLUSÕES}

A bacia hidrográfica do Rio Branco possui uma área drenada de $1027.8 \mathrm{~km}^{2}$. A vazão do canal principal no alto curso foi de $0,626 \mathrm{~m}^{3} / \mathrm{s}$ no período de estiagem e de $6,62 \mathrm{~m}^{3} / \mathrm{s}$ no período chuvoso. No médio curso, foram registrados $2,838 \mathrm{~m}^{3} / \mathrm{s}$ no período de estiagem e $42,30 \mathrm{~m}^{3} / \mathrm{s}$ no período chuvoso. Já no baixo curso houve o registro de $4,861 \mathrm{~m}^{3} / \mathrm{s}$ no período de estiagem e de $126,42 \mathrm{~m}^{3} / \mathrm{s}$ no período chuvoso. O Córrego Bracinho, principal afluente do Rio Branco, com 51,19 km de extensão, registrou vazão de $1,976 \mathrm{~m}^{3} / \mathrm{s}$ durante 
a estiagem e $35,07 \mathrm{~m}^{3} / \mathrm{s}$ durante o período chuvoso. A seção IV foi a que demonstrou a menor vazão: $0,012 \mathrm{~m}^{3} / \mathrm{s}$ durante o período de estiagem e $0,11 \mathrm{~m}^{3} / \mathrm{s}$ no período chuvoso.

Os sedimentos transportados em suspensão variaram entre $40 \mathrm{mg} / \mathrm{L}$ e $280 \mathrm{mg} / \mathrm{L}$ no período de estiagem. Durante o período chuvoso, o maior índice foi de $288 \mathrm{mg} / \mathrm{L}$, na seção XVI, situada na foz do canal principal. A turbidez durante a estiagem variou de 2,23 a 50,6 UTN; no período chuvoso o maior índice foi de 420 UTN, registrado na foz da bacia. A carga sólida em suspensão variou entre 0,02 e 3.146 t/dia-1.

A presença de processos erosivos (voçoroca) contribuiu para aumentar a carga sólida suspensa e a turbidez na seção III nos dois períodos analisados. Quanto à composição granulométrica de sedimentos de fundo, houve distinções entre as seções nos dois períodos, em decorrência das particularidades de cada canal, sendo a areia fina a fração mais encontrada.

O estudo demonstrou que, na carga de sedimentos de fundo, há maior predominância de sedimentos grosseiros no Rio Branco. Esse fato pode ser relacionado à turbulência do fluxo, que faz a argila e o silte serem transportados em solução.

A falta de cobertura vegetal facilita o desprendimento de partículas do solo, aumentando a sedimentação da bacia. $O$ relevo acidentado potencializa a capacidade de transporte de materiais pesados, incluindo seixos, matacões e blocos, além de grande quantidade de areia.

A formação geológica na cabeceira de drenagem deu origem a solos com grande proporção de areia que ficam suscetíveis a processos erosivos, causando assoreamento do leito do Rio Branco..

\section{REFERÊNCIAS}

ANDRADE, L. N. P. S.; SOUZA, C. A.. Sub-bacia hidrográfica do Córrego das Pitas: análise batimétrica e transporte de sedimentos. Geociências, São Paulo, v. 28, n. 4, p.387-400, 2009.

BARRELLA, W.; PETRERE JUNIOR., M.; SMITH, W. S.; MONTAG, L. F. A. As relações entre as matas ciliares, os rios e os peixes. In: RODRIGUES, R. R.; LEITÃO FILHO, H. F.. Matas ciliares: conservação e recuperação. São Paulo: EDUSP; FAPESP, 2000.

BLANTON, P.; MARCUS, W. A. Transportation infrastructure, river confinement, and impacts on floodplain and channel habitat, Yakima and Chehalis rivers, Washington: Geomorphology, v.189, p.55, 2013.

CARVALHO, N. O.; FILIZOLA JUNIOR, N. P.; SANTOS, P. M. C.; Lima, J. E. F. W.. Guia de práticas sedimentométricas. Brasília: ANEEL. 2000.

CHRISTOFOLETTI, A.. Geomorfologia. 2 ed. São Paulo: Edgard Blücher, 1980.

CHRISTOFOLETTI, A.. Geomorfologia fluvial: o canal fluvial. Ed. Edgar Blücher, São Paulo, 1981.

CUNHA, S. B.. Geomorfologia fluvial. In: GUERRA, A. J. T.; CUNHA, S. B.. Geomorfologia: uma atualização de bases e conceitos. 8 ed. Rio de Janeiro: Bertrand Brasil, 2008.
CUNHA, S. B. Bacias hidrográficas. In: CUNHA, S. B.; GUERRA, A. J. T.. Geomorfologia do Brasil. 5 ed. Rio de Janeiro: Bertrand Brasil, 2009.

EMBRAPA. Centro Nacional de Pesquisa de Solos. Manual de métodos de análises de solo. Rio de Janeiro, 1997.

HEITMULLER, F. T.; RAPHELT, N.. The role of sedimenttransport evaluations for development of modeled instream flows: Policy and approach in Texas. Journal of Environmental Management, v.102, p.37-49, 2012.

LIMA, A. G.. Rios de leito rochoso: aspectos geomorfológicos fundamentais. Ambiência, Guarapuava, v.6, n.2, p.339-354, 2010.

NÉGREL, P.; MERLY, C.; GOURCY, L.;CERDAN, O.; PETELETGIRAUD, E.;KRALIK, M.; VEGTER, J.. Soil-Sediment-River Connections: Catchment Processes Delivering Pressures to River Catchments. In: BRILS, J.. Risk-Informed Management of European River Basins. The Handbook of Environmental Chemistry, v.29, 2014. DOI: http://doi.org/10.1007/978-3$\underline{642-38598-8 \quad 2}$

SANTOS, M.;CRUZ, J. S.;SOUZA, C. A.; ROCHA, E. Análise sedimentológica do alto curso da bacia hidrográfica do Córrego Cachoeirinha, sudoeste de Mato Grosso. Revista Geonorte, v.10, n.1, p.162-166, 2014.

SILVA, Y. J. A. B.; DE OLIVEIRA SILVA, M. D. R.; RAMON, J.; CANTALICE, B.; ARAÚJO, A. M.; DA SILVA SOUZA, W. L.; 
MONTEIRO, D.. Transporte de sedimentos produzido na bacia hidrográfica do rio Ipojuca - Porto de Suape. In ENCONTRO NACIONAL DE ENGENHARIA DE SEDIMENTOS, 9. Anais. 2010.

SOUZA, C. A.; CUNHA, S. B.. Evolução das margens do rio Paraguai entre a cidade de Cáceres e a estação ecológica da Ilha de Taiamã, MT. In: SOUZA, C. A.. Bacia Hidrográfica do Rio Paraguai, MT: Dinâmica das águas, uso e ocupação e degradação ambiental. São Carlos: Cubo, 2012.

SOUZA, C. A.; SOUSA, J. B.; LEANDRO, G. R. S.; SILVA, L. A.; SANTANA, M.; SANTOS, M. Sedimentação no rio Paraguai e no baixo curso dos tributários Sepotuba, Cabaçal e Jauru, Mato Grosso, Brasil. In: ENCONTRO DOS GEÓGRAFOS DA AMÉRICA LATINA. Anais. Lima, 2013.
STEVAUX, J. C.; SOUZA, I. A. Floodplain construction in an anastomosed river. Quaternary International, v.114, n.1, p.55-65, 2004

STUDINSKI, J. M.; HARTMAN, K. J.; NILES, J. M.; KEYSER, P. The effects of riparian forest disturbance on stream temperature, sedimentation, and morphology. The International Journal of Aquatic Sciences, Dordrecht, v.686 n.1, p.107-117, 2012.

SUGUIO, K.. Introdução à sedimentologia. São Paulo: Edgar Blucher, 1973.

TRIMBLE, S. W.. Fluvial processes, morphology and sediment budgets in the Coon Creek Basin, WI, USA, 1975-1993.

Geomorphology, v.108, n.1, p.8-23, 2009.

TUCCI, C. E. M.. Hidrologia: ciência e aplicação. 2 ed. Porto Alegre: ABRH; UFRGS, 1997.

A CBPC - Companhia Brasileira de Produção Científica (CNPJ: 11.221.422/0001-03) detém os direitos materiais desta publicação. Os direitos referem-se à publicação do trabalho em qualquer parte do mundo, incluindo os direitos às renovações, expansões e disseminações da contribuição, bem como outros direitos subsidiários. Todos os trabalhos publicados eletronicamente poderão posteriormente ser publicados em coletâneas impressas sob coordenação da Sustenere Publishing, da Companhia Brasileira de Produção Científica e seus parceiros autorizados. Os (as) autores (as) preservam os direitos autorais, mas não têm permissão para a publicação da contribuição em outro meio, impresso ou digital, em português ou em tradução. 